\title{
The effects of six months Persicaria minor extract supplement among older adults with mild cognitive impairment: a double- blinded, randomized, and placebo- controlled trial
}

Huijin Lau', Suzana Shahar ${ }^{1 *}$, Mazlyfarina Mohamad², Nor Fadilah Rajab, Hanis Mastura Yahya', Normah Che Din ${ }^{3}$ and Hamzaini Abdul Hamid ${ }^{4}$

\begin{abstract}
Background: Persicaria minor extract exhibits antioxidant and anti-inflammatory properties and has potential effects on cognitive function and mood. However, the effects of P.minor on brain activation and biomarkers have not been studied among older adults. This multicentre, randomized, double-blinded, placebo-controlled study aimed to investigate the effect of 6 months P.minor extract supplement (Biokesum ${ }^{\oplus}$ ) on cognition, mood, biomarkers, and brain activation among older adults with Mild Cognitive Impairment $(\mathrm{MCl})$.

Method: A total of 36 Malaysian community-dwelling older adults with $\mathrm{MCl}$ (60-75-year-old) were randomized into Biokesum $^{\circledast}(n=18)$ and placebo group $(n=18)$. Each subject consumed one capsule of Biokesum ${ }^{\oplus}\left(250 \mathrm{mg} /\right.$ capsule) $^{2}$ or placebo (maltodextrin, $280 \mathrm{mg} / \mathrm{capsule}$ ) twice daily for 6 months. Cognitive function and mood were assessed at baseline, 3rd, and 6th-month using neuropsychological tests (MMSE, Digit Span, RAVLT, Digit Symbol, and Visual Reproduction) and Profile of Mood State (POMS) questionnaire. Blood lipid profile, fasting blood glucose, and biomarkers (MDA, LPO, COX-2, iNOS, and BDNF) were measured at baseline and 6th month. By the end of the intervention, there were 30 compliers (Biokesum ${ }^{\oplus}: N=15$; Placebo: $N=15$ ) and 6 dropouts. For brain activation assessment, 15 subsamples (Biokesum ${ }^{\oplus}: N=8$; Placebo: $N=7$ ) completed $N$-back and Stroop tasks during fMRI scanning at baseline and 6th month. The dorsolateral prefrontal cortex (Brodmann's area 9 and 46) was identified as a region of interest (ROI) for brain activation analysis using SPM software.

(Continued on next page)
\end{abstract}

\footnotetext{
* Correspondence: suzana.shahar@ukm.edu.my

'Center for Healthy Aging and Wellness, Faculty of Health Sciences, Universiti Kebangsaan Malaysia, Jalan Raja Muda Abdul Aziz, 50300 Kuala Lumpur, Malaysia

Full list of author information is available at the end of the article
}

(C) The Author(s). 2020 Open Access This article is licensed under a Creative Commons Attribution 4.0 International License, which permits use, sharing, adaptation, distribution and reproduction in any medium or format, as long as you give appropriate credit to the original author(s) and the source, provide a link to the Creative Commons licence, and indicate if changes were made. The images or other third party material in this article are included in the article's Creative Commons licence, unless indicated otherwise in a credit line to the material. If material is not included in the article's Creative Commons licence and your intended use is not permitted by statutory regulation or exceeds the permitted use, you will need to obtain permission directly from the copyright holder. To view a copy of this licence, visit http://creativecommons.org/licenses/by/4.0/ The Creative Commons Public Domain Dedication waiver (http://creativecommons.org/publicdomain/zero/1.0/) applies to the data made available in this article, unless otherwise stated in a credit line to the data. 
(Continued from previous page)

Results: Two-way mixed ANOVA analysis showed significant improvements in Visual Reproduction $\|(p=0.012$, partial $\left.\eta^{2}=0.470\right)$, tension $\left(p=0.042\right.$, partial $\left.\eta^{2}=0.147\right)$, anger $\left(p=0.010\right.$, partial $\left.\eta^{2}=0.207\right)$, confusion ( $p=0.041$, partial $\left.\eta^{2}=0.148\right)$, total negative subscales $\left(p=0.043\right.$, partial $\left.\eta^{2}=0.145\right), \operatorname{BDNF}\left(p=0.020\right.$, partial $\left.\eta^{2}=0.179\right)$ and triglyceride $\left(p=0.029\right.$, partial $\left.\eta^{2}=0.237\right)$ following 6 months of Biokesum ${ }^{\circledR}$ supplementation. Preliminary finding also demonstrated significant improvement at 0-back task-induced right DLPFC activation $\left(p=0.028\right.$, partial $\left.\eta^{2}=0.652\right)$ among subsamples in Biokesum ${ }^{\circledast}$ group. No adverse events were reported at the end of the study.

Conclusion: Six months Biokesum ${ }^{\circledR}$ supplementation potentially improved visual memory, negative mood, BDNF, and triglyceride levels among older adults with $\mathrm{MCl}$. Significant findings on brain activation at the right DPLFC must be considered as preliminary.

Trial registration: Retrospectively registered on 30th August 2019 [ISRC TN12417552].

Keywords: Brain-derived neurotrophic factor, fMRI, Medicinal plants, Mild cognitive impairment, Mood

\section{Background}

The rapid growth of the worldwide aging population has resulted in an increase in neurodegenerative disorders, such as Alzheimer's disease, which results in cognitive function, physical functionality, and quality of life impairments [1]. Cognitive functions including memory, attention, processing speed, visuospatial perception, and problem solving deteriorate with age and are affected by both non-modifiable (age and genetics) and modifiable risk factors (lifestyle factors, hypertension, diabetes, and depression) [2-4]. Therefore, adopting a healthy lifestyle behavior is essential to promote cognitive and mental health $[5,6]$.

The presence of phenolic compounds and flavonoids in herbs and medicinal plants are being acknowledged for their potential benefits on human health [7-9]. Several recent studies have reported the beneficial effects of herbs or natural extract supplementation on cognitive performance, mood, biomarkers, and also brain activity. For example, the beneficial effects of coffee fruit extract [10, 11], Ginkgo biloba [12, 13], and curcumin [14, 15] on the brain-derived neurotrophic factor (BDNF), cognitive function and mood of older adults have been reported. Besides, consumptions of aloe polymannose multi nutrients complex, Cistus incanus herbal tea and chayote (Sechium edule) decreased oxidative stress marker such as malondialdehyde and lipoperoxides, inflammation markers tumor necrosis factoralpha (TNF- $\alpha$ ) and also triglyceride level among older adults [16-18]. Brain activity was also improved among healthy adults, $\mathrm{AD}$ and aMCI patients after the consumption of Chinese herbal decoctions $[19,20]$ and multiingredients herbal supplement that consists of Bacopa monniera, Panax quinquefolius ginseng, and whole coffee fruit extract [21].

Persicaria minor (P.minor) is an aromatic plant belongs to the family Polygonaceae, originating from Southeast Asian countries such as Indonesia, Vietnam, Thailand, and Malaysia [22]. P.minor leaf extract was found to have flavonoids such as quercetin, has been suggested to have antioxidant, anti-inflammation [23, 24], and antimicrobial properties [25]. To date, there were only two human studies investigated the effect of P.minor extract on cognitive function, mood, and quality of life. A study conducted by Udani [26] showed a significant improvement in cognitive function and mood after 3 weeks of SuperUlam supplementation. SuperUlam is a proprietary blend of natural ingredients including P.minor extract. Recent research using P.minor extract supplement (LineMinus ${ }^{\mathrm{TM}}$ ) also demonstrated a significant improvement in attention and memory, mood, and quality of life among middle-aged women after 6 weeks of supplementation [27]. The effects of P.minor have never been evaluated on neurotrophin, oxidative stress, and inflammation biomarkers and functional brain activity using functional magnetic resonance imaging (fMRI) especially among older adults with MCI.

To address this knowledge gap, a randomized, doubleblind, placebo-controlled clinical trial was designed and conducted to evaluate the effects of 6 months P.minor extract supplement on cognitive function, mood, neurotrophin, oxidative stress, and inflammation biomarkers as well as fMRI brain activity among older adults with MCI.

\section{Methods}

\section{Study design and ethical approval}

This study was a multicentre, double-blinded, randomized, placebo-controlled trial with allocation ratio $1: 1$, which consists of three visits: (1) visit 1 (baseline), (2) visit 2 (3rd month) and (3) visit 3 (6th month). A total of 36 Malaysian community-dwelling older adults aged 60 to 75 with Mild Cognitive Impairment (MCI) were successfully recruited in this study. Out of 36 participants, 15 volunteered sub-samples participated in an fMRI assessment to evaluate the effect of P.minor extract supplement on brain activity (Biokesum ${ }^{\circ}: N=8$; placebo: $N=7$ ). The Medical Research Ethics Committee of Universiti Kebangsaan Malaysia (MRECUKM) (NN- 2017036) approved the study protocol. Written informed 
consent was obtained from all participants before data collection. This study was also registered under the ISRCTN Registry (ISRCTN12417552) and conducted under Good Clinical Practice Guidelines and the ethical principles of the Declaration of Helsinki.

\section{Sample size calculation}

With a two-sided $5 \%$ significance level and a power of $80 \%$, the calculation for sample size is determined by using a Randomised Controlled Trials formula proposed by Zhong [28]. Regarding the study of Ma et al. [29], the mean difference of Digit Span score between treatment and control groups (3.4) with pooled standard deviation (10.95) were substituted into the formula. The calculated sample size was 15 per group.

\section{Study settings and participants}

Participants were recruited from community-dwelling older adults' population through poster advertising and invitation. Recruitment and data collection process were conducted at multiple senior citizen clubs located in Klang Valley, Malaysia from 11th March 2017 to 4th October 2017. Participants' allocation was based on a simple randomization method using a computergenerated list of random numbers prepared by the investigator with no involvement in the clinical trial. All the study personnel and participants were kept blinded to the group assignment, study product distribution, and trial findings. The manufacturing company carried out the unblinding process after the data analysis was completed.

Potential participants were screened for eligibility based on inclusion and exclusion criteria in a health screening and one-to-one interview session before the start of the intervention. A participant information sheet was distributed to each participant during the screening session to provide relevant information on the clinical trial, which included the objective, study product, procedure, potential benefits, and risks, as well as the rights to refuse or withdraw. Older adults with MCI were

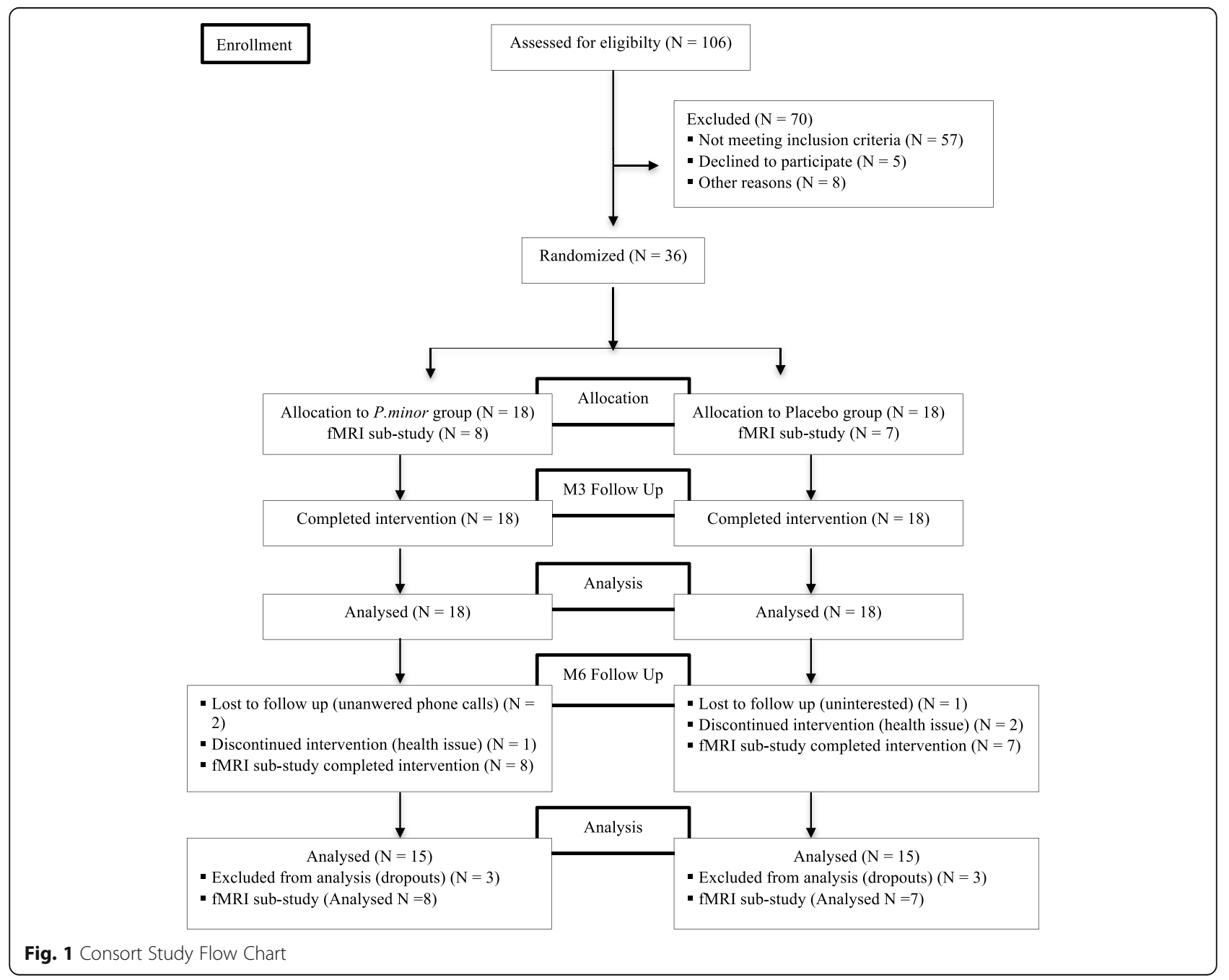


determined based on the criteria published in the previous Malaysian population-based study of a neuroprotective model for healthy longevity using a series of neuropsychological tests [30]. Older adults with selfreported regular consumption of traditional herbs, vitamin or mineral supplements for the past 6 months, selfreported neurodegenerative diseases (i.e., dementia and Parkinson disease), depressive symptoms (score $>5$ in Geriatric Depression Scale) or other serious medical conditions such as renal and kidney failure (based on blood analysis report) were excluded from the study.

Figure 1 showed the consort study flow chart of the study. A total of 106 older adults age $60-75$ years were enrolled and accessed for eligibility. Seventy of them were excluded from the study due to not meeting the inclusion criteria $(n=57)$, declined to participate $(n=5)$ and other personal reasons $(n=8)$. Participants who met the inclusion criteria were randomized into the placebo and Biokesum ${ }^{\circ}$ group, with 18 subjects per arm. All the participants completed the study at baseline and the 3rd-month follow-up $(n=36)$. At the 6th month follow up, there were a total of 3 dropouts from each group due to uninterested to continue the study, lost to follow up, and health issue. In conclusion, the remaining 30 participants completed the 6 months of intervention and were included in the analysis. Per protocol population was used in the analysis of primary and secondary endpoints. All of the sub-samples $(N=15)$ also completed the fMRI assessment at the end of the intervention and were included in the analysis.

\section{Study product}

Biokesum $^{\odot}$ is a patent-pending (P1 2,012,003,882) aqueous extract of $P$. minor supplement provided by the sponsor company Biotropics Malaysia Sdn Bhd. A finished product in the form of a capsule contains $250 \mathrm{mg}$ of Biokesum ${ }^{\circ}$ extract was developed and registered under the National Pharmaceutical Control Bureau (NPCB) with the registration number of MAL14015033T. Each capsule of Biokesum ${ }^{\circ}$ contains bioactive compounds included quercetin-3-glucuronide (not less than $0.45 \%$ ), quercitrin (not less than $0.15 \%$ ), and total phenolic content (not less than $100 \mathrm{mg} \mathrm{GAE} / \mathrm{g}$ $\mathrm{dE}$ ). Toxicity, changes in behavior, and mortality were not observed in Winstar rats up to $2000 \mathrm{mg} / \mathrm{kg}$ doses in acute oral toxicity study [31].

The participants were randomized to received either P.minor extract supplement (Biokesum $\left.{ }^{\circ}\right)(250 \mathrm{mg} / \mathrm{cap}-$ sule) or sensory-identical placebo composed of maltodextrin $(280 \mathrm{mg} /$ capsule) administered by the researcher. The maltodextrin has been used as the major placebo substance generally and considered as Generally Regarded As Safe (GRAS) status [32, 33]. Previous study also suggested that maltodextrin is safe for human consumption with acute no observed adverse effect level (NOAEL) of $0.8 \mathrm{~g} / \mathrm{kg}$ body weight for men and more than $1.0 \mathrm{~g} / \mathrm{kg}$ body weight for women [34]. Although there was an animal study suggested that excessive ingestion of maltodextrin impaired spatial recognition memory and increased weight gain in Wistar rats [35], however, the amount of maltodextrin given to the animals were between $409 \mathrm{~g}$ to $447 \mathrm{~g}$, which is much higher than the dose given in this study.

Both of the study products were manufactured in a Good Manufacturing Practice (GMP) facility. The participants were instructed to take the study products one capsule twice a day, in the morning and afternoon followed by a meal. Participants were reminded to take the study products through daily text messages and phone calls. Compliance of the subjects was monitored regularly by performing capsule count during followups. The compliance rate of this study was $85.6 \%$.

\section{Study procedure}

The participants were determined for their physical health (blood pressure, pulse rate, height and body weight measurement), cognitive function and mood status at baseline (visit 1), visit 2 and visit 3. Dietary macronutrient and micronutrient intake of the participants was also assessed using the 7-days Diet History Questionnaire (DHQ) and adjusted as confounding factors in the statistical analysis. At baseline and visit 3, participants were requested to fast at least $10-12 \mathrm{~h}$ before the day of data collection for blood sampling purposes. Subsamples who have volunteered to participate in neuroimaging study were also required to undergo an fMRI assessment at baseline and visit 3 . The study products were distributed at baseline and visit 2 . Adverse events were also recorded at the end of visits 2 and 3.

\section{Cognitive and mood assessments}

The primary objective of this study was to determine the effect of $P$. minor extract supplement on cognitive function and mood state of older adults with MCI (Table 1). A series of cognitive tests (Mini-Mental State of Examination, Digit Span, Rey Auditory Verbal Learning Test, Digit Symbol, and Visual Reproduction) were used to assess global cognitive function, working and episodic memory, cognitive processing speed and visual memory of the participants. Their mood for the past 7 days was also accessed using the Profile of Mood State (POMS) questionnaire.

\section{Blood biochemical profile and biomarkers measurements}

The secondary objective of this study was to determine the effect of the $P$. minor extract supplement on biomarkers and fMRI brain activation (Table 1). Biochemical profile and biomarkers measurement were carried 
Table 1 Primary and secondary outcomes

\begin{tabular}{ll}
\hline Task & Cognitive domains and mood status assessments \\
\hline Primary Outcomes & \\
MMSE & Global Cognitive function \\
Digit Span & Attention, short term, and working memory \\
RAVLT & Verbal immediate memory \\
VR I \& II & Non-verbal memory and visuospatial function \\
Digit symbol substitution & Psychomotor speed \\
POMS & Tension, depression, anger, vigor, esteem related affect, fatigue and confusion \\
Secondary Outcomes & \\
Biomarkers & BDNF, Oxidative stress (LPO, MDA), Inflammatory markers (iNOS, COX2) \\
Biochemical blood profile & Lipid profile and blood glucose profile \\
fMRI & Brain activation at the dorsolateral prefrontal cortex \\
\hline
\end{tabular}

MMSE mini-mental state examination, RAVLT rey auditory verbal learning test, $V R$ visual reproduction, $P O M S$ profile of mood state, $B D N F$ brain-derived neurotrophic factor, LPO lipid hydroperoxides, MDA malondialdehyde, iNOS inducible nitric oxide synthase, COX2 cyclooxygenase 2, fMRI functional magnetic resonance imaging

out at baseline and visit 3. Participants were required to fast overnight for at least $10 \mathrm{~h}$ for blood sampling purposes conducted by a trained phlebotomist. The collected blood samples were stored in an icebox for the delivery purpose to a local laboratory for analysis. Biochemical blood profile included lipid profile, blood sugar profile, liver function test, and renal profile were analyzed at medical laboratory Quantum Diagnostic Sdn. Bhd., Selangor, Malaysia. The serum samples were stored under $-80{ }^{\circ} \mathrm{C}$ before biomarkers analysis. Determination of biomarkers included oxidative stress markers (malondialdehyde (MDA) and lipid hydroperoxide (LPO)), inflammation markers (inducible nitric oxide synthase (iNOS) and cyclooxygenase-2 (COX-2)) and brain-derived neurotrophic factor (BDNF) were carried out using commercial ELISA kits (Elabscience, Houston, Texas, USA) at Faculty of Health Sciences, Universiti Kebangsaan Malaysia, Kuala Lumpur, Malaysia.

\section{Neuroimaging study}

Functional Magnetic Resonance Imaging (fMRI) is a non-invasive technique used to determine the brain activation areas. It measures the changes in blood oxygen level in the active areas of the brain through the Blood Oxygen Level Dependent (BOLD) fMRI technique. Eligible participants were invited to the Department of Radiology, Universiti Kebangsaan Malaysia Medical Centre (UKMMC), Cheras, Kuala Lumpur, Malaysia to undergo fMRI assessment conducted by a trained radiographer. Participants' consents were obtained before the scan.

All of the sub-samples completed the anatomical scans lasting for $3 \mathrm{~min}$ before fMRI tasks. Participants were required to complete two visual memory tasks, i.e., N-back and Stroop Color-Word task, in a session during the scan. The task paradigms were presented using
Superlab5 (Cedrus Corporation, San Pedro, California, USA). A brief description of the study procedure and memory tasks were given to the participants before the scan.

\section{N-Back}

$\mathrm{N}$-back is widely used to access working memory. The task requires a cascade of cognitive processes included encoding and temporary storage of information, progressive updating incoming information. The N-back task with two paradigms: 0 - and 1- back was used in this study to assess the working memory of older adults. Both 0- and 1- back consists of four task blocks (Fig. 2). A total of 15 trials for each block were displayed using a projection screen during each condition. In 0-back condition, participants need to identify the position of the target (red box) that is similar to the one as shown at the beginning of each block. In 1-back condition, participants need to identify the position of the target that is similar as the one preceding it. The stimulus was presented on a projection screen for 2000 milliseconds, with an inter-stimulus interval (ISI) of $30 \mathrm{~s}$.

\section{Stroop task}

The Stroop task is a neuropsychological test used to assess the cognitive processing speed, flexibility, interference, and inhibition. In our study, the Stroop task consists of two paradigms. A total of four task blocks with 15 trials each was displayed in each paradigm. In the first paradigm, participants were presented with a series of color words (black, blue, yellow, green, red). These words appeared in different colors, sometimes matching the word (e.g., the word "blue", displayed in blue ink), and sometimes not matching the word (i.e: the word "blue", displayed in red ink). Participants were required to indicate the color in which the word is written, 


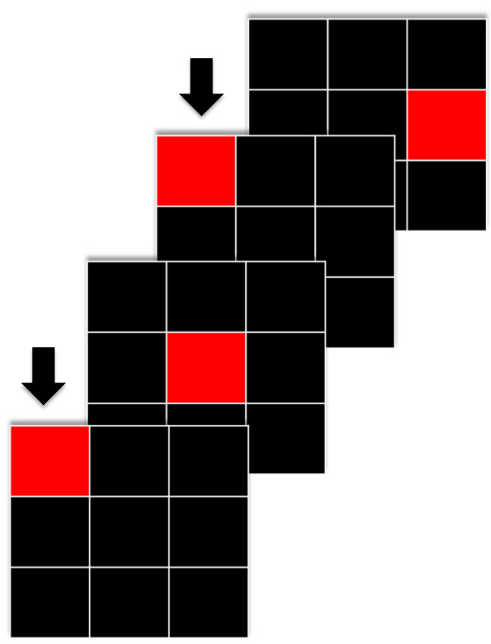

0-BACK

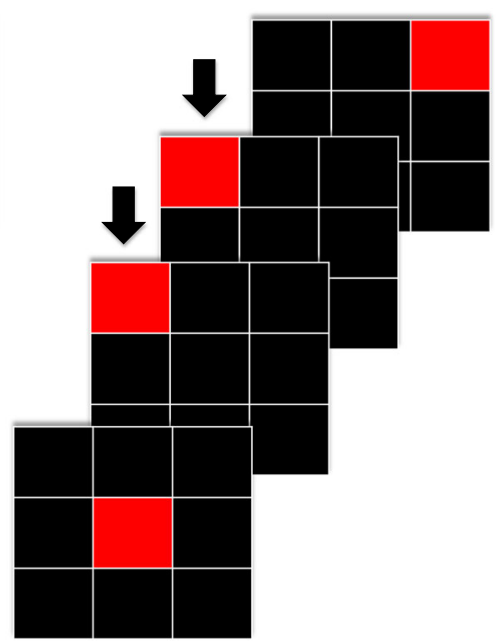

1-BACK

Fig. 2 Schematic overview of N-back spatial task. The N-back spatial task consists of two paradigms: 0- and 1-back condition

whether or not that matches the word itself. In the second paradigm, a white color word was displayed under a color word printed in different colors. The meaning of lower word sometimes is congruent with the color of the upper word (i.e: the lower word written as red, the upper word "black", displayed in red ink) or sometimes is incongruent with the color of the upper word (i.e: the lower word written as red, the upper word "red", displayed in green ink) (Fig. 3). Participants were required to indicate whether the color of the upper word corresponds with the meaning of the lower word or not. Participants shall not pay attention to the word but the color. Stimuli were presented on a projection screen for 2000 milliseconds, with an inter-stimulus interval of $30 \mathrm{~s}$.
(A) BLUE

(C)

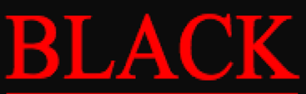
RED
(B)

\section{BLUE}

(D)

\section{RED BLUE}

Fig. 3 Schematic overview of Stroop task. (a) Matched color-word (b) Unmatched color-word (c) Color of the upper word matched with the meaning of the bottom word (d) Color of the upper word unmatched with the meaning of the bottom word 


\section{Image acquisition}

A 3.0-T magnetic resonance scanner (MAGNETOM, Trio, Siemens, Erlagen, Germany) was used to acquire the fMRI data. $\mathrm{T}_{1}$-weighted image (repetition time $(\mathrm{TR})=1900 \mathrm{~ms}$, echo time $(\mathrm{TE})=2.35 \mathrm{~ms}$, voxel dimensions $1.0 \times 1.0 \times 1.0 \mathrm{~mm}, 250 \times 250$ voxels, 176 slices, slice thickness $=1 \mathrm{~mm}$ ) and $\mathrm{T} 2 *$ weighted image during N-back and Stroop tasks $(\mathrm{TR}=3000 \mathrm{~ms}, \mathrm{TE}=30 \mathrm{~ms}, 3$ $\mathrm{mm}$ isotropic voxels, flip angle $=90^{\circ}, 27$ slices, slice thickness $=4 \mathrm{~mm}$ ) were obtained from the subjects. A total of 180 volumes were acquired for N-back and 170 volumes for the Stroop task. Results and raw images were then saved for further analysis using MATLAB (Mathworks Inc., Natick, MA, USA) and Statistical Parametric Mapping (SPM) software (SPM12; Wellcome Department of Cognitive Neurology, London, UK).

\section{Pre-processing and functional imaging data analysis}

Pre-processing and data analysis was performed using SPM software implemented in MATLAB. Prior to analysis, the functional images were realigned for motion correction and resliced to the mean image of the series. These functional images were then co-registered to the participants's mean T1-weighted image, estimated against a standardized Montreal Neurological Institute (MNI) stereotaxic space. The spatial normalisation procedure utilized a 12-parameter affine transformation with a spatial transformation matrix. To reduce the intersubject variability, a spatial smoothing process with a 6-mm full-width half-maximum isotropic Gaussian kernel was conducted for all of the functional volumes.

Using the WFU PickAtlas library, the bilateral dorsolateral prefrontal cortex (DLPFC) (Brodmann's area BA 9 and 46) was chosen as the region of interest (ROI). Percent signal change of the regions with peak activation (peak T-statistics) was extracted using the Marsbar tool, corrected for family-wise error (FWE), $p<0.05$.

\section{Statistical analysis}

All the data were analyzed using Statistical Package for Social Science (SPSS) version 22 (IBM, Armonk, New York, US). Independent $t$-test was employed to determine the differences in percentage mean change between the Biokesum ${ }^{\odot}$ and the placebo group. The group by time effects were determined using two-way mixed ANOVA. Confounding factors such as age, caffeinated beverages intake, smoking status, educational level, baseline cognitive function (MMSE score), and nutrients intake (total calorie intake, vitamin $\mathrm{A}, \mathrm{C}$, thiamin, riboflavin, niacin, and iron) were controlled during the statistical analysis. Significant value was set at $p<0.05$.

\section{Results}

A total of 36 participants participated in this study at baseline. At the end of the intervention, a total of 3 participants from each study group were dropped from the study and leaving a total of 30 participants completed the study and data analysis. The dropouts were mainly due to loss of interest to continue the intervention. Other unidentified possible reasons could be healthrelated problems, personal problems, lack of time, or lack of motivation. As shown in Table 2, sociodemographic and self-reported health status were compared for both intervention and placebo groups. No significant differences were observed between the two groups at baseline. An additional file shows more details on baseline dietary nutrient intake (See Additional file 1). The findings of two-way mixed ANOVA intervention effects of the cognitive domains and mood assessments, blood biochemical profile and biomarkers, and fMRI brain activation were showed in the additional files.

\section{Cognitive domains and mood assessments}

Significant intervention effect was observed in Visual Reproduction II test $\left(p=0.012\right.$, partial $\left.\eta^{2}=0.470\right)$ (See Additional file 1). The percentage mean difference of Visual Reproduction II score was increased following 6 months of intervention in the Biokesum ${ }^{\bullet}$ group (+ $9.80 \%)$ but decreased in the placebo group (-6.80\%) (Fig. 4). No significant intervention effects were observed in other cognitive parameters included Digit Span, RAVLT, and Digit Symbol $(p>0.05)$.

Significant intervention effect was also observed in mood states included tension $\left(p=0.042\right.$, partial $\eta^{2}=$ $0.147)$, anger $\left(p=0.010\right.$, partial $\left.\eta^{2}=0.207\right)$, confusion $\left(p=0.041\right.$, partial $\left.\eta^{2}=0.148\right)$ and total negative subscales $\left(p=0.043\right.$, partial $\left.\eta^{2}=0.145\right) \quad$ (See Additional file 2). The percentage of mean differences was significantly reduced in tension $(-30.91 \%)$, anger ($52.95 \%)$, confusion $(-18.7 \%)$ and total of negative subscales $(-33.43 \%)$ in the Biokesum ${ }^{\odot}$ group but increased in placebo group by $+55 \%$, $+51.87 \%$, + $53.62 \%$, $+33.12 \%$, respectively at the end of the study (Fig. 4). No significant intervention effects were observed in other mood status included vigour, esteem related affect, total positive subscales and total mood disturbance $(p>0.05)$.

\section{Blood biochemical profile and biomarkers}

Significant intervention effect was observed in triglycerides (TG) concentration $\left(p=0.029\right.$, partial $\left.\eta^{2}=0.537\right)$ (See Additional file 3). The TG percentage of mean difference was significantly reduced by $19.05 \%$ in the Biokesum $^{\otimes}$ group but increased by $10.17 \%$ in the placebo group (Fig. 5). Brain-derived neurotrophic factor (BDNF) also demonstrated significant intervention effect $(p=$ 
Table 2 Comparison of baseline sociodemographic and self-reported health status between P.minor and placebo groups

\begin{tabular}{|c|c|c|c|c|}
\hline & P.minor $(N=18)$ & Placebo $(N=18)$ & Total $(N=36)$ & $p$ value ${ }^{\dagger}$ \\
\hline$\overline{\mathrm{Age}^{\ddagger}}$ & $66.89 \pm 4.00$ & $65.94 \pm 3.61$ & $66.42 \pm 0.63$ & 0.462 \\
\hline \multicolumn{5}{|l|}{ Gender } \\
\hline Male & $3(16.7)$ & $5(27.8)$ & $8(22.2)$ & \multirow[t]{2}{*}{0.423} \\
\hline Female & $15(83.3)$ & $13(72.2)$ & $28(77.8)$ & \\
\hline \multicolumn{5}{|l|}{ Ethnicity } \\
\hline Malay & $16(88.9)$ & $17(94.4)$ & $33(91.7)$ & \multirow[t]{3}{*}{0.220} \\
\hline Chinese & $2(11.1)$ & $0(9.1)$ & $2(5.6)$ & \\
\hline Indian & $0(0)$ & $1(5.6)$ & $1(2.7)$ & \\
\hline \multicolumn{5}{|l|}{ Educational Level } \\
\hline Not attending school & $1(5.6)$ & $3(16.7)$ & $4(11.1)$ & \multirow[t]{5}{*}{0.293} \\
\hline Primary school & $8(44.4)$ & $5(27.8)$ & $13(36.1)$ & \\
\hline Secondary school & $9(50.0)$ & $7(38.9)$ & $16(44.4)$ & \\
\hline Certificate/ Diploma & $0(0)$ & $2(11.1)$ & $2(5.6)$ & \\
\hline Degree & $0(0)$ & $1(5.6)$ & $1(2.8)$ & \\
\hline \multicolumn{5}{|l|}{ Marital Status } \\
\hline Married & $9(50.0)$ & $13(72.2)$ & $22(61.1)$ & \multirow[t]{2}{*}{0.305} \\
\hline Widow/Widower & $9(50.0)$ & $5(27.8)$ & $14(38.9)$ & \\
\hline \multicolumn{5}{|l|}{ Smoking Status } \\
\hline Yes & $1(5.6)$ & $1(4.5)$ & $2(5.6)$ & \multirow[t]{2}{*}{1.000} \\
\hline No & $17(94.4)$ & $17(94.4)$ & $34(94.4)$ & \\
\hline \multicolumn{5}{|c|}{ Regular Supplement Consumer } \\
\hline Yes & $7(38.9)$ & $9(50.0)$ & $16(44.4)$ & \multirow[t]{2}{*}{0.738} \\
\hline No & $11(61.1)$ & $9(50.0)$ & $20(55.6)$ & \\
\hline \multicolumn{5}{|c|}{ Caffeinated Beverage Consumer } \\
\hline Yes & $17(94.4)$ & $17(94.4)$ & $34(94.4)$ & \multirow[t]{2}{*}{1.000} \\
\hline No & $1(5.6)$ & $1(5.6)$ & $2(5.6)$ & \\
\hline \multicolumn{5}{|l|}{ Working Status } \\
\hline Yes & $2(11.1)$ & $2(11.1)$ & $4(11.1)$ & \multirow[t]{2}{*}{1.000} \\
\hline No & $16(88.9)$ & $16(88.9)$ & $32(88.9)$ & \\
\hline \multicolumn{5}{|l|}{ Hypertension } \\
\hline Yes & $9(50.0)$ & $9(50.0)$ & $18(50.0)$ & \multirow[t]{2}{*}{1.000} \\
\hline No & $9(50.0)$ & $9(50.0)$ & $18(50.0)$ & \\
\hline \multicolumn{5}{|l|}{ Diabetes } \\
\hline Yes & $4(22.2)$ & $3(16.7)$ & $7(19.4)$ & \multirow[t]{2}{*}{1.000} \\
\hline No & $14(72.8)$ & $15(83.3)$ & $29(80.6)$ & \\
\hline \multicolumn{5}{|l|}{ Hyperlipidemia } \\
\hline Yes & $8(44.4)$ & $11(61.1)$ & $19(52.8)$ & \multirow[t]{3}{*}{0.176} \\
\hline No & $7(38.9)$ & $7(28.9)$ & $14(38.9)$ & \\
\hline Not Sure & $3(16.7)$ & $0(0.0)$ & $3(8.3)$ & \\
\hline
\end{tabular}

${ }^{\dagger}$ Crosstabs Chi-square test, not significant at $p>0.05$

${ }^{\ddagger}$ Independent t-test, not significant at $p>0.05$

0.020 , partial $\eta^{2}=0.563$ ) (See Additional file 2). The percentage mean difference was slightly increased by $2.03 \%$ in the Biokesum ${ }^{\circ}$ group but decreased by $19.19 \%$ in the placebo group at the end of the intervention (Fig. 5).
Other blood biochemical parameters included blood glucose profile, MDA, LPO, COX-2, and iNOS did not show any significant improvements following 6 months of intervention $(p>0.05)$. 


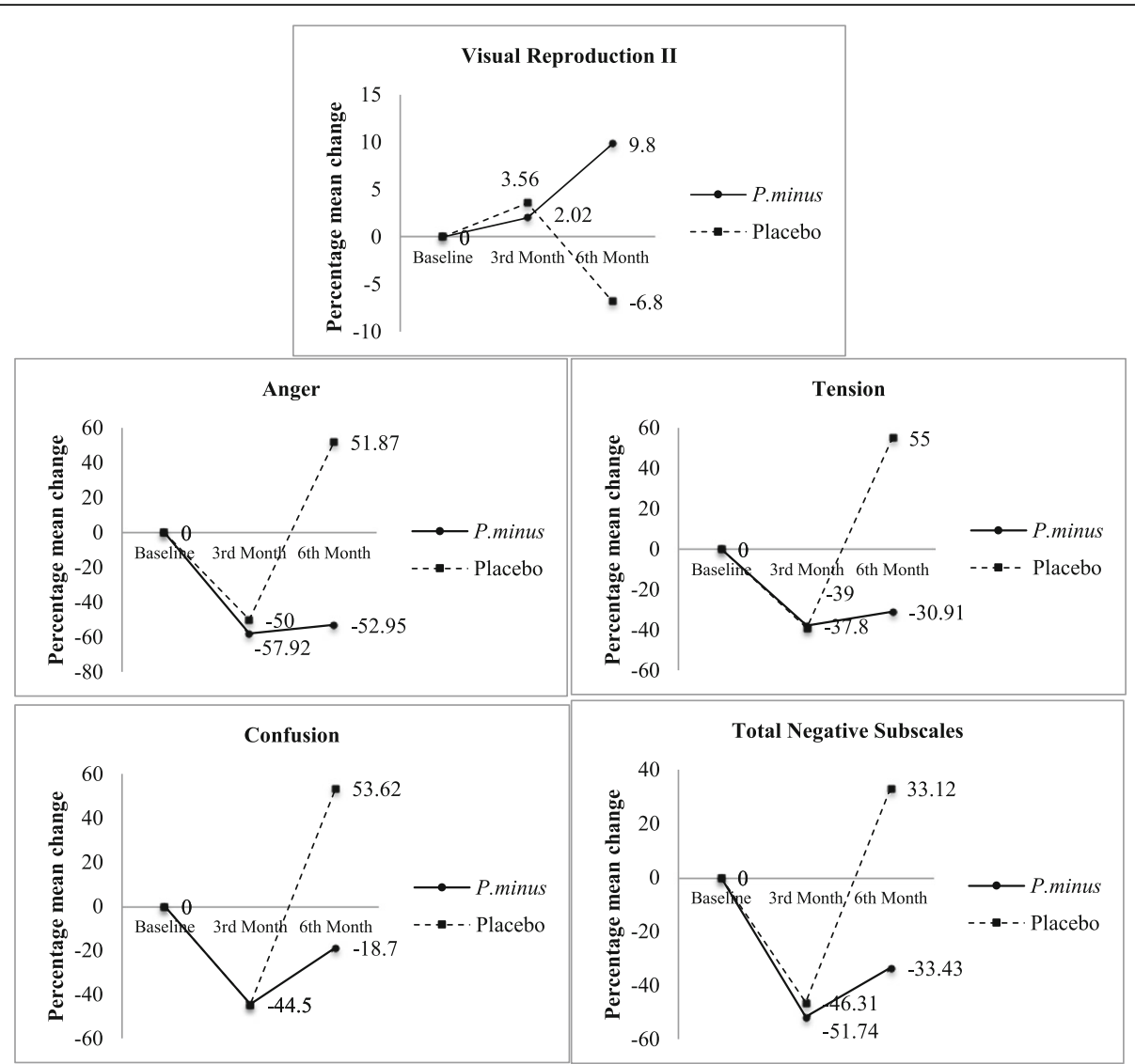

Fig. 4 Percentage mean change of significant cognitive and mood parameters from baseline to 3rd-month and 6th-month follow-ups. After 6 months of intervention, percentage mean change of VRII was increased by $9.8 \%$ in the Biokesum ${ }^{\circledR}$ group and decreased by $6.8 \%$ in the placebo group. Percentage mean change of anger was decreased by $52.95 \%$ in the Biokesum ${ }^{\oplus}$ group, but increased by $51.87 \%$ in the placebo group. Percentage mean change of tension was decreased by $30.91 \%$ in the Biokesum ${ }^{\circledR}$ group, but increased by $55 \%$ in the placebo group. Percentage mean change of confusion was decreased by $44.5 \%$ in the Biokesum ${ }^{\oplus}$ group, but increased by $53.62 \%$ in the placebo group. Percentage mean change of total negative subscales was decreased by $33.43 \%$ in the Biokesum ${ }^{\oplus}$ group, but increased by $33.12 \%$ in the placebo group (Two-way mixed anova, $p<0.05$ )

\section{fMRI brain activation}

0-back task-induced right DLPFC activation showed significant intervention effect $\left(p=0.028\right.$, partial $\left.\eta^{2}=0.652\right)$ (See Additional file 4). The percentage mean difference of right DLPFC percent signal change was increased by
$19.61 \%$ during the 0-back task in the Biokesum ${ }^{\circ}$ group but decreased by $47 \%$ in the placebo group (Fig. 6). No significant intervention effects were observed in other parameters included 1-back and Stroop task-induced DLPFC activation $(p>0.05)$.

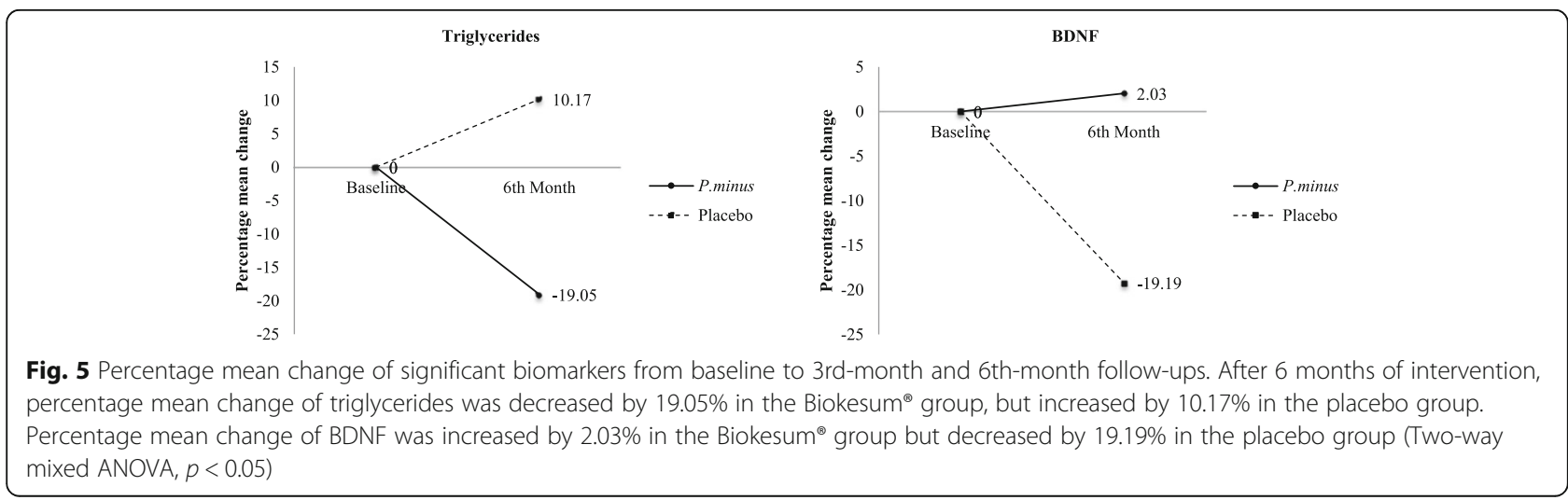




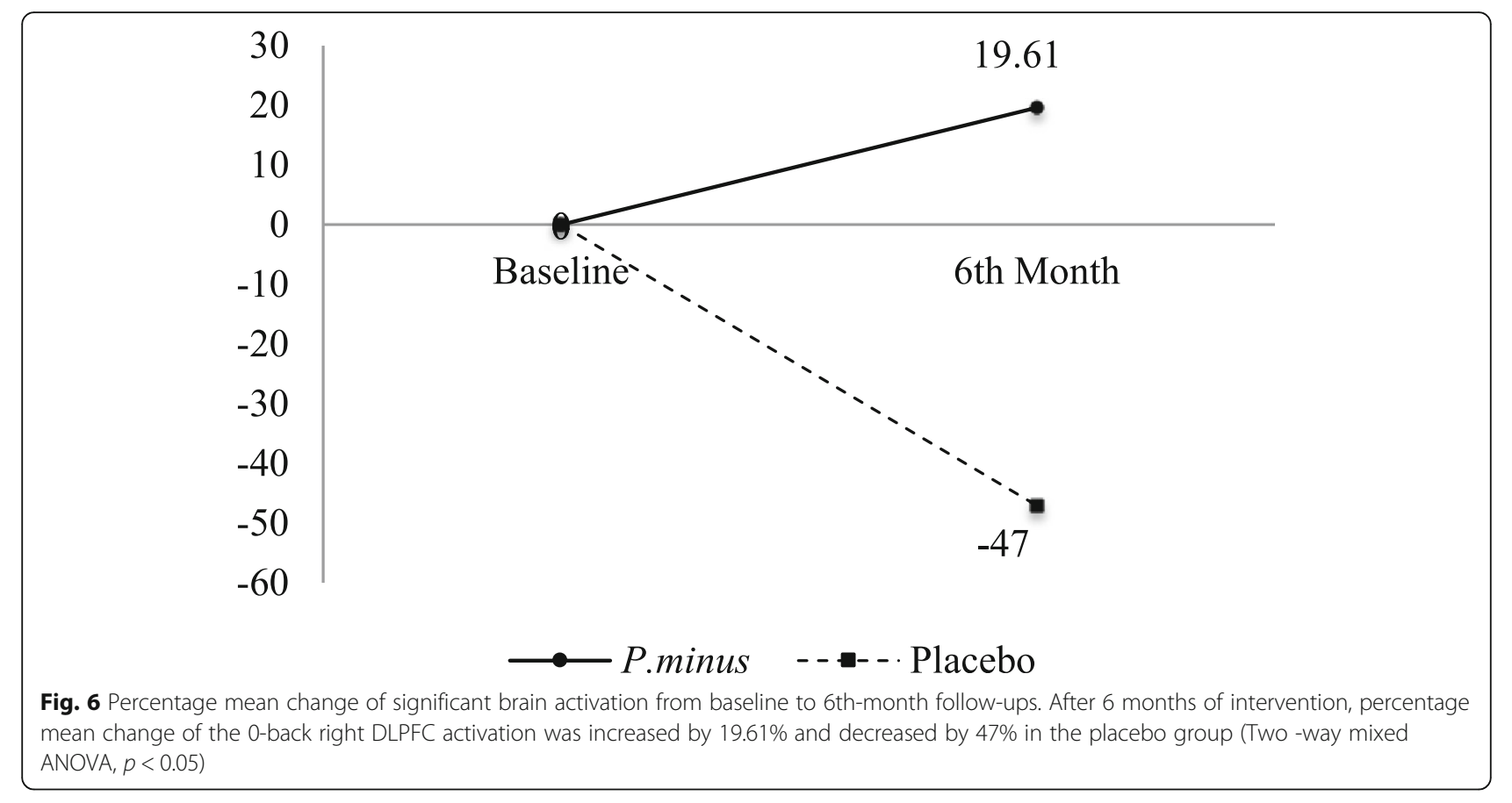

Given this significant finding, the tasks-induced right DLPFC activation of the Biokesum ${ }^{\circ}$ group were displayed on a volume rendered brain using ROI analysis at BA 9 and 46 (FWE, $p<0.05$ ) (Fig. 7). As compared to baseline, more areas were activated included inferior frontal gyrus (IFG), middle frontal gyrus (MFG), and precentral gyrus (PrG) during the 0-back task following $P$. minor extract supplementation. IFG was the only region activated during the 1-back task at baseline, but activation was also observed at MFG after 6 months. Baseline activations were also observed at PrG and MFG during the Stroop task and at PrG and IFG after 6 months.

\section{Adverse events}

No serious adverse events were reported in this study.

\section{Discussion}

The primary finding of this research provided partial support for our hypothesis that 6 months $P$. minor extract (Biokesum ${ }^{\circ}$ ) supplement showed significant enhancement in visual memory but not other cognitive domains such as attention, verbal memory, and processing speed among older adults with MCI. Biokesum ${ }^{\circ}$ supplement consists of phenolic compound quercetin 3-Oglucuronide $(\mathrm{Q} 3 \mathrm{G})$, a glucuronide conjugate of quercetin. It has been suggested that Q3G has a potential beneficial effect on cognitive health due to its ability in increasing protein secretion of BDNF, promoting neural stem cells migration and neurogenesis [36], inhibiting endoplasmic reticulum stress which contributed to oxidative stress and attenuating tau protein phosphorylation $[37,38]$.

A previous study using a similar $P$. minor supplement (previously known as LineMinus $\left.{ }^{\mathrm{Tm}}\right)(500 \mathrm{mg} /$ day) also reported significant improvements in Digit Span, Comprehensive Trail Making Test, and CNS vital signs in cognitive flexibility and executive function among healthy middle-aged women after 6 weeks of consumption [27]. Together with the current finding, both short and long duration consumption of $P$. minor extract supplement has the potential to improve cognitive domains such as attention, cognitive flexibility and executive function among middle-aged adults and visual memory among older adults with MCI. Nevertheless, we did not find any significant improvements in other cognitive domains. It could be due to the visual working memory impairment that emerged before the verbal working memory impairment among individuals with MCI as suggested by Emrani et al. [39]. Therefore, the effect of the $P$. minor extract supplement may be more notable in the visual memory domain as compared to other cognitive domains in this study.

Significant improvements were observed in most of the negative mood status particularly tension, anger, confusion, and total negative subscales in the present study. Our findings were in line with the previous study [27], which also demonstrated significant improvements in tension, depression, anger, and total mood disturbance among healthy middle-aged women with mood disturbance. Quercetin and Q3G have been suggested to have an anti-depression ability [40]. These flavonoids 


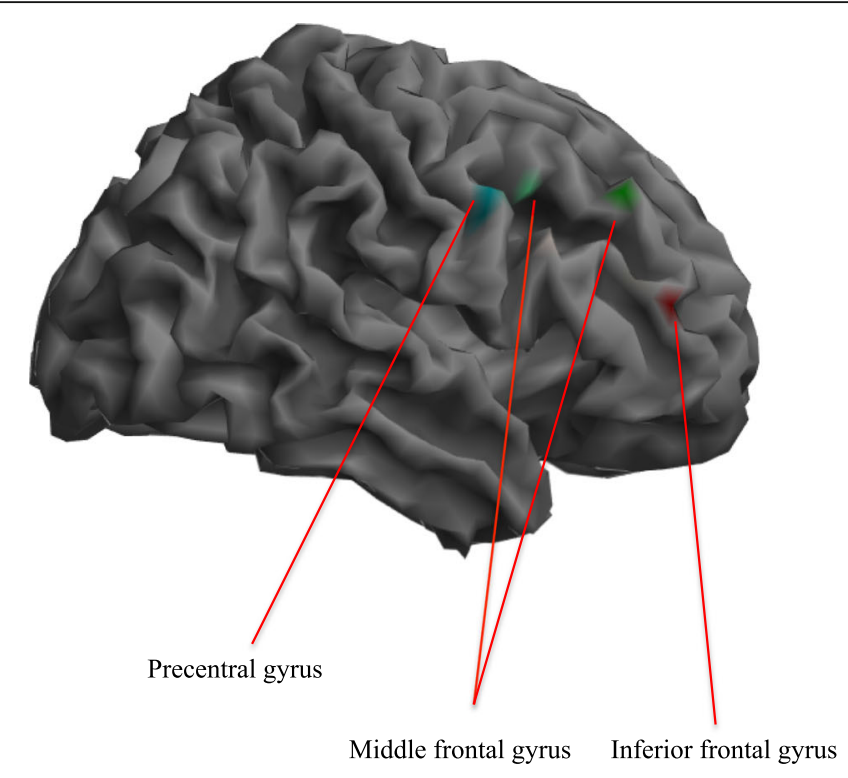

A

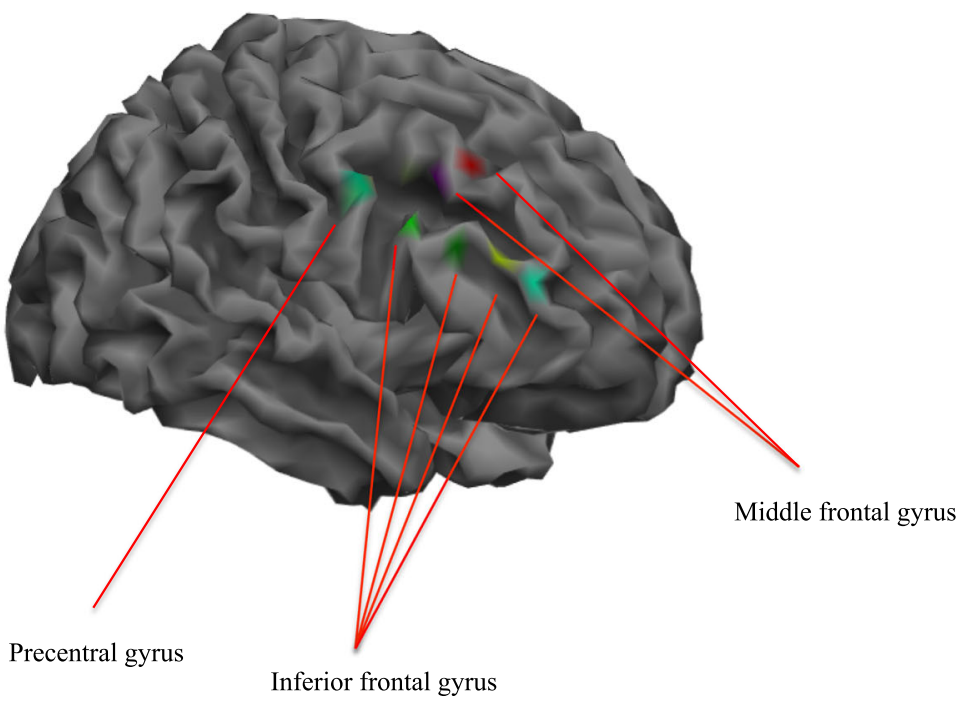

B

Fig. 7 Right DLPFC activation during 0-back, 1-back and Stroop tasks on a volume rendered brain at baseline (a) and 6th month (b), family-wise error (FWE) corrected $p<0.05$. More activation was observed during the brain tasks at the right DLPFC regions included precentral gyrus, inferior frontal gyrus, and middle frontal gyrus at 6th-month intervention when compared to baseline. (Blue area: 0-back task; Red area: 1-back task; Green area: Stroop task; Magenta area: 0-back and 1-back tasks; Cyan area: 0-back and Stroop tasks; Yellow area: 1-back and Stroop tasks)

were reported to have an impact on gammaaminobutyric acid (GABA) receptors producing sedation, anxiolytic, or anticonvulsive effects [41]. Also, quercetin can inhibit monoamine oxidase (MAO), which involved in mood disorder, depression, and oxidative stress $[42,43]$. This can be supported by the recent animal study, which reported that 14 days of ingestion of quercetin $(20 \mathrm{mg} / \mathrm{kg})$ could reverse stress-induced anxiety and depression in mice [44]. Another study by Metha et al. [45] demonstrated that mice ingested with quercetin $(30 \mathrm{mg} / \mathrm{kg}, 21$ days) reversed the effects of chronic unpredicted stress on depression and anxiety. Therefore, the presence of the flavonoid in the supplement might explain its beneficial effects in reducing negative mood among older adults with MCI.

To our knowledge, this is also the first study to examine the effect of the P. minor extract supplement on biomarkers. Our findings revealed that the BDNF concentration was significantly higher in the Biokesum ${ }^{\odot}$ group as compared to the placebo group following 
6 months of intervention. Previous animal studies [36, 46] highlighted that quercetin and Q3G significantly increased the mRNA expression and secretion of BDNF in rats, which contribute to the neural stem cell proliferation. The possible underlying mechanism could be the quercetin activates BDNF-TrkB and its associated signaling pathway, which eventually, results in phosphorylation of CREB, followed by an increase in extracellular signal-regulated kinase (ERK) and BDNF $[47,48]$. Therefore, quercetin interactions with these pathways may be responsible for its role in the central nervous system.

We also postulate that the improvement in the BDNF level may have an indirect effect on the mood findings reported in the present study. Reduction in BDNF levels has been reported in persons with depression [49]. Increased anxiety-related behaviors, decreased ventromedial prefrontal cortex volume and memory deficits have been observed in mice with BDNF Val66Met polymorphism [50, 51]. These findings suggested that the BDNF Val66Met polymorphism might cause smaller prefrontal cortex development and increased the risk of cognitive decline and mood disorders. Nevertheless, minimal increment in the BDNF level has been noted in this study and we are aware that the significant result could be possibly due to the greater reduction in the level as seen in the placebo group.

Triglyceride concentration was also significantly reduced following 6 months of $P$. minor extract supplementation. This finding was consistent with Yahya et al. [27], which also reported a significant reduction in lipid profile, particularly total cholesterol to HDL ratio. More than half of the subjects in this study were reported to have hyperlipidemia (52.8\%). Hyperlipidemia may induce the production of the reactive oxygen species (ROS) from the mitochondrial electron system lead to the generation of lipid peroxide radicals and lipid peroxidation. Increased lipid peroxidation is thought to be a consequence of oxidative stress and it is associated with Alzheimer's disease [52]. Our findings can be supported by the preclinical study, which suggested that $P$. minor extract possessed an antihyperlipidemic effect by significantly reduced lipid levels (total cholesterol, TG, and LDL) in a rat model [53]. It has been suggested it could be due to the flavonoids myricetin and quercetin that present in the $P$. minor extract. A recent animal study showed that high-fat induced obese rat that consumed a quercetin-rich formulation supplement presented a much less lipid accumulation and smaller size of adipocytes [54]. A study by Seo et al. [55] has been suggested that quercetin inhibits lipid accumulation and obesityinduced inflammation in both cell and animal models. Mitogen-activated protein kinase (MAPK) signaling factors played a role in adipogenesis and inflammation and that adipokines MCP-1 and TNF- $\alpha$ increased the recruitment of macrophages in adipose tissue. Quercetin was found to have the ability in suppressing the MAPK signaling factors (extracellular signal-regulated kinases 1 and $2($ ERK1/2), JNK, p38MAPK, MCP-1, and TNF- $\alpha)$ that played a role in adipogenesis and inflammation. The findings also revealed that quercetin inhibits the secretion of the inflammatory cytokines IL-1 $\beta$ and IL- 6 and stimulates the secretion of the anti-inflammatory cytokine, IL-10 [55]. Therefore, quercetin may play a role in reducing the TG level in the present study. Other than its antihyperlipidemic effect, quercetin was reported to possess antidiabetic effect by inhibiting intestinal glucose absorption, increasing insulin secretion, improved glucose utilization in peripheral tissue through increased protein expression and phosphorylation of insulin receptor [56]. However, we did not find any significant findings on the blood glucose profile. The lack of observed effects of the $P$. minor extract supplement maybe because the present study was not focused on the subjects with T2DM. It also remains possible that the effect of herbal supplementation on the biochemical profile can vary according to dosage, duration, and the forms of supplementation given to the subjects.

The previous in vitro and animal studies that demonstrated strong antioxidant and anti-inflammation influences of $P$. minor extract did not support our findings on antioxidant and anti-inflammation biomarkers. George et al. [57] highlighted that the ethanolic P. minor extract significantly inhibited cyclooxygenase-1 (COX-1) and lipooxygenase (5-LOX) activities, however, the inhibitory effect on cyclooxygenase-2 (COX-2) was minimal. The same research also reported that aqueous $P$. minor extract (100 and $300 \mathrm{mg} / \mathrm{kg}$ ) significantly reduced inflammation of carrageenan-induced rat paw edema. Despite promising results in in-vitro and animal studies, the results of the present study raise questions about the generalizability of these findings to human populations. One of the possible reasons could be the interindividual variation in quercetin bioavailability reduced the antioxidant and anti-inflammation capacity $[58,59]$. It remains plausible that the significant reduction in lipid levels might suppress lipid peroxidation, which in turn contributes to the insignificant findings on oxidative stress and inflammation markers.

The effect of $P$. minor extract supplement on fMRI brain activation was examined among subsamples in the present study. A significant increase in the activation was observed at the right DLPFC during the 0-back task following 6 months of supplementation. Activation at the right DLPFC has been suggested to be more dominant in visuospatial working memory [33, 60]. According to Barbey et al. [61], right DLPFC is responsible for manipulating information beyond working memory in a wider range of reasoning contexts, such as arithmetic 
and spatial reasoning, goal-directed behavior, and decision-making. These cognitive skills are important for older adults to maintain their quality of life. A previous animal study reported that flavonoid quercetin could protect mice against a reduction in cerebral blood flow and memory impairment [62]. Quercetin also possessed the ability to protect human brain microvascular endothelial cells from toxicity induced by fibrillar amyloid- $\beta$, a signature hallmark of Alzheimer's disease [63]. Progressive accumulation of amyloid- $\beta$ in and around blood vessels in the brain disrupted Blood-Brain Barrier (BBB) permeability, which in turn reduces cerebral blood flow to the brain [64]. Sufficiency of cerebral blood flow is important to maintain brain function, and insufficiency causes neurodegeneration [65].

Activation at right DLPFC, particularly right precentral gyrus, middle frontal gyrus, and inferior frontal gyrus were observed in the present study. Similarly, in a study conducted by Kwon et al. [66], the subjects also demonstrated more activation in the right hemisphere such as middle frontal gyrus and inferior frontal gyrus during visuospatial N-back task. Middle frontal gyrus (MFG) is associated with age-related decline in episodic memory retrieval. It can retrieve information about previously experienced events or items in rich contextually details [67]. Right middle frontal gyrus specifically activated during learning of non-verbal information, for example patterns. While left MFG activated in response to literary than numeracy [68]. Right precentral gyrus has also been implicated in response inhibition [69]. Therefore, it is not surprising that these regions showed more activation during visual brain tasks.

The strengths and limitations of the current study must be considered. The primary strength of the current study was the use of a randomized, double-blinded placebo-controlled method to access the efficacy of P.minor extract supplement on various aspects from neuropsychological assessments to blood biomarkers and neuroimaging for 6 months. Furthermore, this study was focused on older adults with mild cognitive impairment who are at high risk of getting Alzheimer's disease. In addition, the use of neuroimaging technique is another strength of this study. An fMRI is a noninvasive imaging tool and there is no exposure to ionizing radiation. Therefore, it is suitable to be used in the studies involving older adults. Besides, it can also provide an insight into the underlying cerebral hemodynamic response to herbal supplementation. Thus, fMRI is more reliable and sensitive as compared to objective cognitive assessments when determining the cerebral response changes among those with risk of cognitive impairment [70]. It is also important to note some limitations of the present study. First, the functional evidence was limited to small sample size. Therefore, the present functional finding must be considered as preliminary. Besides, we used self-report to evaluate participants' mood and this may lead to recall and selective bias. Future studies would benefit from using a larger and more diverse sample size to confirm the neuroprotective and mood regulation effects of P.minor extract supplementation.

\section{Conclusions}

The findings from the current research suggested that 6 months of P.minor extract (Biokesum ${ }^{\circ}$ ) supplementation can significantly improve visuospatial memory, tension, anger, confusion, total negative subscales, triglyceride and BDNF level among older adults with MCI. Significant finding on the right DLPFC activation was based on subsamples only. Therefore, the results must be considered preliminary until such effects can be studied further in a larger sample size. These findings may serve as a knowledge base for other herbal or natural extracts supplementation studies in the future.

\section{Supplementary information}

Supplementary information accompanies this paper at https://doi.org/10. 1186/s12906-020-03092-2.
Additional file 1. Baseline dietary nutrients intake.
Additional file 2. Intervention effect of neurocognitive assessments and POMS.
Additional file 3. Intervention effect of blood biochemical profile and biomarkers.
Additional file 4. Intervention effect of fMRI brain activation (percent signal change).

\section{Abbreviations}

ALT: Alanine transferase; BDNF: Brain-derived neurotrophic factor; BOLD: Blood oxygen level dependent; COX2: Cyclooxygenase 2; DHQ: Diet history questionnaire; DLPFC: Dorsolateral prefrontal cortex; ELISA: Enzymelinked immunosorbent assay; FBC: Full blood count; FBG: Fasting blood glucose; fMRI: Functional magnetic resonance imaging; GMP: Good manufacturing practice; HbA1c: Glycated hemoglobin A1c; HOMA: Homeostatic model assessment; iNOS: Inducible nitric oxide synthase; LP: Lipid profile; LFT: Liver function test; MCl: Mild cognitive impairment; MDA: Malondialdehyde; MFG: Middle frontal gyrus; MMSE: Mini-mental state of examination; NPCB: National Pharmaceutical Control Bureau; P. minor: Persicaria minor; POMS: Profile of mood state; RAVLT: Rey auditory verbal learning test; TG: Triglyceride; VR: Visual reproduction

\section{Acknowledgments \\ We acknowledge the contributions of the co-researchers, field workers, phle- botomists, and research and scientific officers. We also thank the participants and their family members, community leaders, and the local authorities for their cooperation throughout recruitment and data collection processes.}

\section{Authors' contributions}

HL was responsible for overall conceptualization, acquisition of data, analysis of data, initial and final draft. SS was responsible for overall

conceptualization, initial draft, and revising the draft for content. MM and $\mathrm{HAH}$ were responsible for conceptualization in the fMRI aspect and revising the draft for content. NFR was responsible for conceptualization in the biochemical aspect and revising the draft for content. HMY and NCD were responsible for conceptualization in the neurocognitive aspect and revising draft for content. All the authors have read and approved the final manuscript. 


\section{Funding}

The study was supported by a grant from Biotropics Sdn. Bhd, Selangor, Malaysia (grant number: NN-2017-036). The funding body was responsible for the design of the study.

\section{Availability of data and materials}

The datasets used and/or analysed during the current study available from the corresponding author on reasonable request.

\section{Ethics approval and consent to participate}

The study protocol has been approved by the Research Ethics Committee Universiti Kebangsaan Malaysia (RECUKM) (Reference number: UKM PPI/111/ 8/JEP-2016-611). Written informed consent was also obtained from all participants before the data collection.

\section{Consent for publication}

Not applicable.

\section{Competing interests}

The authors declare that they have no competing interests.

\section{Author details}

${ }^{1}$ Center for Healthy Aging and Wellness, Faculty of Health Sciences, Universiti Kebangsaan Malaysia, Jalan Raja Muda Abdul Aziz, 50300 Kuala Lumpur, Malaysia. ${ }^{2}$ Centre for Diagnostic and Applied Sciences, Faculty of Health Sciences, Universiti Kebangsaan Malaysia, Jalan Raja Muda Abdul Aziz, 50300 Kuala Lumpur, Malaysia. ${ }^{3}$ Center for Rehabilitation Sciences, Faculty of Health Sciences, Universiti Kebangsaan Malaysia, Jalan Raja Muda Abdul Aziz, 50300 Kuala Lumpur, Malaysia. ${ }^{4}$ Department of Radiology, Faculty of Medicine, Universiti Kebangsaan Malaysia Medical Center, Jalan Yaacob Latif, Bandar Tun Razak, 56000 Batu 9 Cheras, Kuala Lumpur, Malaysia.

Received: 29 March 2020 Accepted: 20 September 2020 Published online: 19 October 2020

\section{References}

1. Livingston G, Sommerlad A, Orgeta V, Costafreda SG, Huntley J, Ames D. Dementia prevention, intervention, and care. Lancet. 2017:390:2673-734.

2. Klimova B, Valis M, Kuca K. Cognitive decline in normal aging and its prevention: a review on non-pharmacological lifestyle strategies. Clin Interv Aging. 2017;12:903-10.

3. Gallagher D, Kiss A, Lanctot KL, Herrmann N. Toward prevention of Mild Cognitive Impairment in older adults with depression: an observational study of potentially modifiable risk factors. J Clin Psychiatry. 2018;80: $18 \mathrm{~m} 12331$.

4. D'Cunha NM, McKune AJ, Panagiotakos DB, Georgousopoulou EN, Thomas J, Mellor DD. Evaluation of dietary and lifestyle changes as modifiers of S100beta levels in Alzheimer's disease. Nutr Neurosci. 2019;22:1-18.

5. Lai DWL, Chan KC, Xie XJ, Daoust GD. The experience of growing old in chronic mental health patients. Aging Ment Health. 2019;24:1514-22.

6. Seddon N, D'Cunha NM, Mellor DD, McKune AJ, Georgousopoulou EN, Panagiotakos DB, et al. Effects of Curcumin on cognitive function-a systematic review of randomized controlled trials. Explor Res Hypothesis Med. 2019;4(1):1.

7. Kumar S, Pandey AK. Chemistry and biological activities of flavonoids: an overview. ScientificWorld Journal. 2013;2013:162750.

8. Wink M. Modes of action of herbal medicines and plant secondary metabolites. Medicines (Basel). 2015;2(3):251-86.

9. Tungmunnithum D, Thongboonyou A, Pholboon A, Yangsabai A. Flavonoids and other phenolic compounds from medicinal plants for pharmaceutical and medical aspects: an overview. Medicines (Basel). 2018;5(3):93.

10. Reyes-Izquierdo T, Nemzer B, Shu C, Huynh L, Argumedo R, Keller R, et al. Modulatory effect of coffee fruit extract on plasma levels of brain-derived neurotrophic factor in healthy subjects. Br J Nutr. 2013;110(3):420-5.

11. Robinson JL, Hunter JM, Reyes-Izquierdo T, Argumedo R, Brizuela-Bastien J, et al. Cognitive short- and long-term effects of coffee cherry extract in older adults with mild cognitive decline. Neuropsychol Dev Cogn B Aging Neuropsychol Cogn. 2019:1-17.

12. Lasaite L, Spadiene A, Savickiene N, Skesters A, Silova A. The effect of Ginkgo biloba and Camellia sinensis extracts on psychological state and glycemic control in patients with type 2 diabetes mellitus. Nat Prod Commun. 2014;9(9):1345-50.

13. Zhang XY, Zhang WF, Zhou DF, Chen DC, Xiu MH, Wu HR, et al. Brainderived neurotrophic factor levels and its Val66Met gene polymorphism predict tardive dyskinesia treatment response to Ginkgo biloba. Biol Psychiatry. 2012;72(8):700-6.

14. Rainey-Smith SR, Brown BM, Sohrabi HR, Shah T, Goozee KG, Gupta VB, et al. Curcumin and cognition: a randomised, placebo-controlled, double-blind study of community-dwelling older adults. Br J Nutr. 2016;115(12):2106-13.

15. Scholey A, Cox K, Pipingas A, White D. A highly bioavailable curcumin extract improves neurocognitive function and mood in healthy older people: a 12- week randomised, double-blind, placebo-controlled trial (OR32-05-19). Curr Dev Nutr. 2019;3(Supplement_1):nzz052.OR32-05-19.

16. Martin A, Stillman J, Miguez MJ, et al. The effect of dietary supplementation on brain-derived neurotrophic factor and cognitive functioning in Alzheimer's dementia. J Clin Transl Res. 2017;3:337-43.

17. Rosado-Pérez J, Aguiñiga-Sánchez I, Santiago-Osorio E, Mendoza-Núñez VM. Effect of Sechium edule var. nigrum spinosum (Chayote) on oxidative stress and pro-inflammatory markers in older adults with metabolic syndrome: an exploratory study. Antioxidants (Basel). 2019;8:146.

18. Kuchta A, Konopacka A, Waleron K, Viapiana A, Wesołowski M, Dąbkowski K, et al. The effect of Cistus incanus herbal tea supplementation on oxidative stress markers and lipid profile in healthy adults. Cardiol J. 2019.

19. Zhang J, Wang Z, Xu S, Chen Y, Chen K, Liu L, Wang Y, Guo R, Zhang Z. The effects of CCRC on cognition and brain activity in aMCl patients: a pilot placebo controlled BOLD fMRI study. Curr Alzheimer Res. 2014;5:484-93.

20. Lin C, Zhou Z, Xu J, Li Q, Guo J, Long M, Wu D, Zhang Y. Changes of brain activity during a functional magnetic resonance imaging stroop task study: effect of Chinese herbal formula in Alzheimer's disease. Eur J Integr Med. 2017;16:46-53.

21. Best T, Clarke C, Nuzum N, Teo WP. Acute effects of combined Bacopa, American ginseng and whole coffee fruit on working memory and cerebral haemodynamic response of the prefrontal cortex: a double-blind, placebocontrolled study. Nutr Neurosci. 2019:1-12.

22. Vikram P, Chiruvella KK, Ripain $H_{\mathrm{H}}$, Arifullah M. A recent review on phytochemical constituents and medicinal properties of kesum (Polygonum minus Huds.). Asian Pac J Trop Biomed. 2014;4(6):430-5.

23. George $\mathrm{A}, \mathrm{Ng}$ CP, O'Callaghan $\mathrm{M}$, Jensen GS, Wong HJ. In vitro and ex-vivo cellular antioxidant protection and cognitive enhancing effects of an extract of Polygonum minus Huds (Lineminus ${ }^{\mathrm{TM}}$ ) demonstrated in a Barnes maze animal model for memory and learning. BMC Complement Altern Med. 2014;14(1):161.

24. Wan Yahaya WA, Abu Yazid N, Mohd Azman NA, Almajano MP. Antioxidant activities and Total phenolic content of Malaysian herbs as components of active packaging film in beef patties. Antioxidants (Basel). 2019;8(7):204.

25. Abubakar MA, Zulkifli RM, Hassan WN, Shariff AH, Malek NA, Zakaria Z, et al. Antibacterial properties of Persicaria minor (Huds.) ethanolic and aqueousethanolic leaf extracts. J Appl Pharm Sci. 2015;5:050-6.

26. Udani JK. Effects of SuperUlam on supporting concentration and mood: a randomized, double-blind, placebo-controlled crossover study. Evid Based Complement Altern Med. 2013;2013:238454.

27. Yahya HM, Shahar S, Ismail SNA, Aziz AF, Che Din N, Abdul Hakim BN. Mood, cognitive function and quality of life improvements in middle aged women following supplementation with Polygonum Minus extract. Sains Malaysiana. 2017;46:245-54.

28. Zhong B. How to calculate sample size in randomized controlled trial? J Thoracic Dis. 2009;1:51-4.

29. Ma F, Wu T, Zhao J, Han F, Marseglia A, Liu H, Huang G. Effects of 6-month folic acid supplementation on cognitive function and blood biomarkers in mild cognitive impairment: a randomized controlled trial in China. J Gerontol Series A. 2015;10:1376-83.

30. Lau H, Shahar S, Hussin N, Kamarudin MZ, Hamid TA, Mukari SZ, Rajab NF, et al. Methodology approaches and challenges in population-based longitudinal study of a neuroprotective model for healthy longevity. Geriatr Gerontol Int. 2019;19:233-9.

31. Ming YK, Zulkawi NB, Vandana Kotak C, Choudhary YK. Acute and sub-acute oral toxicity of Polygonum minus aqueous extract (Biotropics ${ }^{\circledast}$ PM101) in Wistar rats. Int J Pharm Pharm Sci. 2013;5(2):120-4.

32. Rowe RC, Sheskey PJ, Quinn ME. Handbook of pharmaceutical excipients. London: 6th edition, pharmaceutical press; 2009. p. 506-9. 
33. Wang YR, Liu SF, Shen YC, Chen CL, Huang CN, Pan TM, Wang CK. A randomized, double-blind clinical study to determine the effect of ANKASC IN 568 plus on blood glucose regulation. J Food Drug Anal. 2017;25(2):40916.

34. Yoshikawa Y, Kishimoto Y, Tagami H, Kanahori S. Assessment of the safety of hydrogenated resistant maltodextrin: reverse mutation assay, acute and 90day subchronic repeated oral toxicity in rats, and acute no-effect level for diarrhea in humans. J Toxicol Sci. 2013;38(3):459-70.

35. Kendig MD, Lin CS, Beilharz JE, Rooney KB, Boakes RA. Maltodextrin can produce similar metabolic and cognitive effects to those of sucrose in the rat. Appetite. 2014;77:1-12

36. Baral S, Pariyar R, Kim J, Lee HS, Seo J. Quercetin-3-O-glucuronide promotes the proliferation and migration of neural stem cells. Neurobiol Aging. 2017; 52:39-52.

37. Wu CH, Yang MY, Wang CJ. Quercetin-3-O-glucuronide inhibits doxorubicin resistance by reducing endoplasmic reticulum stress in hepatocellular carcinoma cells. J Funct Foods. 2019;54:301-9.

38. Chen J, Deng X, Liu N, Li M, Liu B, Fu Q, Qu R, et al. Quercetin attenuates tau hyperphosphorylation and improves cognitive disorder via suppression of ER stress in a manner dependent on AMPK pathway. J Funct Foods. 2016;22:463-76

39. Emrani S, Wasserman V, Matusz E, Miller D, Lamar M, Price CC, Ginsberg TB, et al. Visual versus verbal working memory in statistically determined patients with mild cognitive impairment: on behalf of the consortium for clinical and epidemiological neuropsychological data analysis (CENDA). J Int Neuropsychol Soc. 2019;25(10):1001-10.

40. Bashir Ml, Kaz Abdul Aziz NH, Mohamed Noor DA. Possible antidepressant potential of a cognitive enhancer Polygonum minus based on its major chemical constituents in leaf part. Drug Intervention Today. 2020;13:549-57.

41. Pathak L, Agrawal Y, Dhir A. Natural polyphenols in the management of major depression. Expert Opin Investig Drugs. 2013;22:863-80.

42. Baul HS, Rajiniraja M. Mechanistic study of inhibition of monoamine oxidase-B by quercetin as the potential therapeutic strategy for Parkinson's disease: an in silico approach. J Comput Methods Sci Eng. 2018;18:1067-73.

43. Herraiz T, Guillen H. Monoamine oxidase-A inhibition and associated antioxidant activity in plant extracts with potential antidepressant actions. Biomed Res Int. 2018;1:1-10.

44. Samad N, Saleem A, Yasmin F, Shehzad MA. Quercetin protects against stress-induced anxiety- and depression-like behavior and improves memory in male mice. Physiol Res. 2018:67(5):795-808.

45. Mehta V, Verma P, Sharma N, Sharma A, Thakur A, Malairaman U. Quercetin, ascorbic acid, caffeine and ellagic acid are more efficient than rosiglitazone, metformin and glimepiride in interfering with pathways leading to the development of neurological complications associated with diabetes: a comparative in-vitro study. Bull Fac Pharmacy Cairo Univ. 2017;55(1):115-21.

46. Rahvar M, Owji AA, Mashayekhi FJ. Effect of quercetin on the brain-derived neurotrophic factor gene expression in the rat brain. Bratislavske lekarske listy. 2018;119(1):28-31.

47. Jakaria M, Azam S, Jo SH, Kim IS, Dash R, Choi DK. Potential therapeutic targets of Quercetin and its derivatives: its role in the therapy of cognitive impairment. J Clin Med. 2019;8(11):1789.

48. Sharma P, Kumar A, Singh D. Dietary flavonoids interaction with CREB-BDNF pathway: an unconventional approach for comprehensive management of epilepsy. Curr Neuropharmacol. 2019;17(12):1158-75.

49. Yoshida T, Ishikawa M, Niitsu T, Nakazato M, Watanabe $H$, Shiraishi $T$, et al. Decreased serum levels of mature brain-derived neurotrophic factor (BDNF), but not its precursor proBDNF, in patients with major depressive disorder. PLoS One. 2012;7(8):e42676.

50. Chen $Z Y$, Jing $D$, Bath $K G$, leraci A, Khan T, Siao CJ, et al. Genetic variant BDNF (Val66Met) polymorphism alters anxiety-related behavior. Science. 2006;314(5796):140-3.

51. Yu H, Wang Y, Pattwell S, Jing D, Liu T, Zhang Y, et al. Variant BDNF Val66Met polymorphism affects extinction of conditioned aversive memory. J Neurosci. 2009;29(13):4056-64.

52. Bradley-Whitman MA, Lovell MA. Biomarkers of lipid peroxidation in Alzheimer disease (AD): an update. Arch Toxicol. 2015;89(7):1035-44

53. Christapher PV, Parasuraman S, Raj PV, Mohammed Saghir SA, Asmawi MZ, Vikneswaran M. Influence of extracting solvent on pharmacological activity and cytotoxicity of Polygonum minus, a commonly consumed herb in Southeast Asia. Pharmacogn Mag. 2016;12(Suppl 4):S424-s430.
54. Ting Y, Chang WT, Shiau DK, Chou PH, Wu MF, Hsu CL. Antiobesity efficacy of Quercetin-Rich supplement on diet-induced obese rats: effects on body composition, serum lipid profile, and gene expression. J Agric Food Chem. 2018:66(1):70-80.

55. Seo MJ, Lee YJ, Hwang JH, Kim KJ, Lee BY. The inhibitory effects of quercetin on obesity and obesity-induced inflammation by regulation of MAPK signaling. J Nutr Biochem. 2015;26(11):1308-16.

56. Shi GJ, Li Y, Cao QH, Wu HX, Tang XY, Gao XH, et al. In vitro and in vivo evidence that quercetin protects against diabetes and its complications: a systematic review of the literature. Biomed Pharmacother. 2019;109:108599.

57. George A, Chinnappan S, Chintamaneni M, Kotak CV, Choudhary Y, Kueper T, Radhakrishnan AK. Anti-inflammatory effects of Polygonum minus (Huds) extract (Lineminus ${ }^{\mathrm{TM}}$ ) in in-vitro enzyme assays and carrageenan induced paw edema. BMC Complement Altern Med. 2014;14:355.

58. Almeida AF, Borge GIA, Piskula M, Tudose A, Tudoreanu L, Valentová K, Williamson G, Santos CN. Bioavailability of quercetin in humans with a focus on interindividual variation. Compr Rev Food Sci Food Saf. 2018;17(3):71431.

59. Rich GT, Buchweitz M, Winterbone MS, Kroon PA, Wilde PJ. Towards an understanding of the low bioavailability of quercetin: a study of its interaction with intestinal lipids. Nutrients. 2017:9(2):111.

60. Giglia G, Brighina F, Rizzo S, Puma S, Indovino S, Maccora S, et al. Anodal transcranial direct current stimulation of the right dorsolateral prefrontal cortex enhances memory-guided responses in a visuospatial working memory task. Funct Neurol. 2014;29(3):189-93.

61. Barbey AK, Koenigs M, Grafman J. Dorsolateral prefrontal contributions to human working memory. Cortex. 2013:49(5):1195-205.

62. Tota S, Awasthi H, Kamat PK, Nath C, Hanif K. Protective effect of quercetin against intracerebral streptozotocin induced reduction in cerebral blood flow and impairment of memory in mice. Behav Brain Res. 2010;209(1):73-9.

63. Li Y, Zhou S, Li J, Sun Y, Hasimu H, Liu R, et al. Quercetin protects human brain microvascular endothelial cells from fibrillar beta-amyloid1-40-induced toxicity. Acta Pharm Sin B. 2015;5(1):47-54.

64. Kyrtsos CR, Baras JS. Modeling the role of the Glymphatic pathway and cerebral blood vessel properties in Alzheimer's disease pathogenesis. PLoS One. 2015;10(10):e0139574.

65. Hotta H. Chapter 1 - Neurogenic control of parenchymal arterioles in the cerebral cortex. In: Masamoto K, Hirase H, Yamada K, editors. Progress in Brain Research. 225. Amsterdam: Elsevier; 2016. p. 3-39.

66. Kwon H, Reiss AL, Menon V. Neural basis of protracted developmental changes in visuo-spatial working memory. Proc Natl Acad Sci U S A. 2002; 99(20):13336-41.

67. Rajah MN, Languay R, Valiquette L. Age-related changes in prefrontal cortex activity are associated with behavioural deficits in both temporal and spatial context memory retrieval in older adults. Cortex. 2010;46(4):535-49.

68. Koyama MS, O'Connor D, Shehzad Z, Milham MP. Differential contributions of the middle frontal gyrus functional connectivity to literacy and numeracy. Sci Rep. 2017;7(1):17548.

69. Garavan H, Ross TJ, Murphy K, Roche RA, Stein EA. Dissociable executive functions in the dynamic control of behavior: inhibition, error detection, and correction. Neurolmage. 2002;17(4):1820-9.

70. Bondi MW, Houston WS, Eyler LT, Brown GG. fMRI evidence of compensatory mechanisms in older adults at genetic risk for Alzheimer disease. Neurology. 2005;64(3):501-8.

\section{Publisher's Note}

Springer Nature remains neutral with regard to jurisdictional claims in published maps and institutional affiliations. 